
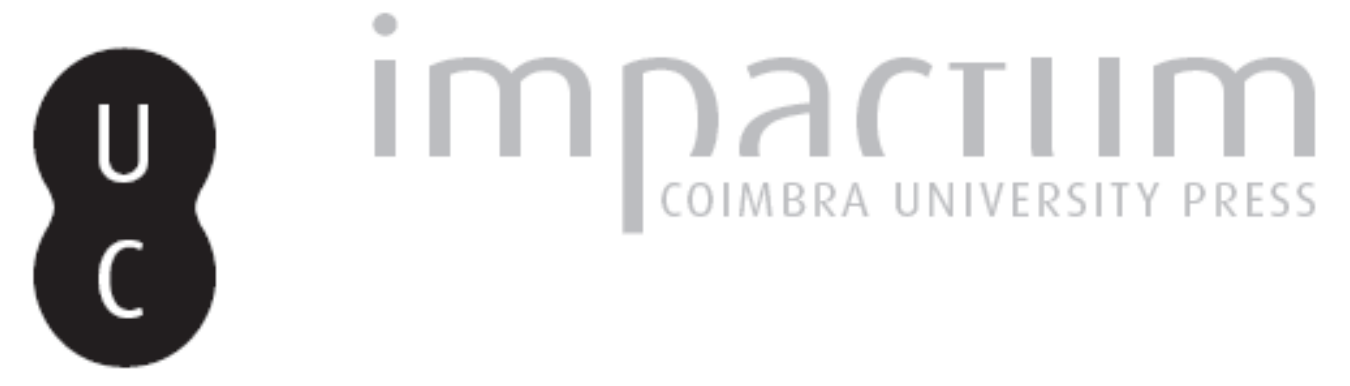

\title{
Responsabilidade civil extracontratual por danos causados por robôs autónomos: breves reflexões
}

\author{
Autor(es): $\quad$ Ferreira, Ana Elisabete
}

Publicado por: Imprensa da Universidade de Coimbra

URL

persistente:

URI:http://hdl.handle.net/10316.2/43559

DOI:

DOI:https://doi.org/10.14195/1647-8630_27_3

Accessed : $\quad$ 26-Apr-2023 16:14:29

A navegação consulta e descarregamento dos títulos inseridos nas Bibliotecas Digitais UC Digitalis, UC Pombalina e UC Impactum, pressupõem a aceitação plena e sem reservas dos Termos e Condições de Uso destas Bibliotecas Digitais, disponíveis em https://digitalis.uc.pt/pt-pt/termos.

Conforme exposto nos referidos Termos e Condições de Uso, o descarregamento de títulos de acesso restrito requer uma licença válida de autorização devendo o utilizador aceder ao(s) documento(s) a partir de um endereço de IP da instituição detentora da supramencionada licença.

Ao utilizador é apenas permitido o descarregamento para uso pessoal, pelo que o emprego do(s) título(s) descarregado(s) para outro fim, designadamente comercial, carece de autorização do respetivo autor ou editor da obra.

Na medida em que todas as obras da UC Digitalis se encontram protegidas pelo Código do Direito de Autor e Direitos Conexos e demais legislação aplicável, toda a cópia, parcial ou total, deste documento, nos casos em que é legalmente admitida, deverá conter ou fazer-se acompanhar por este aviso.

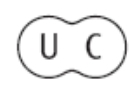


ISSN: 1645-0760

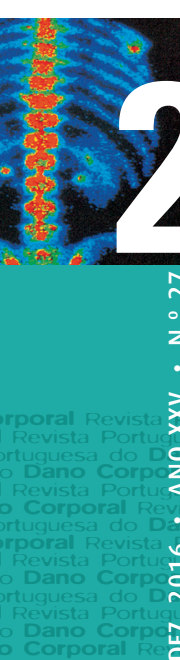

REVISTA PORTU/GUESA
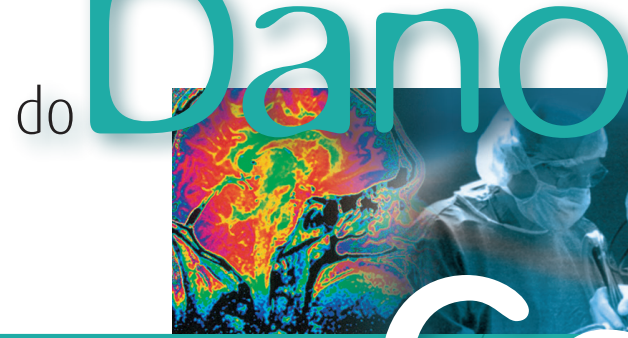

N

z.

希ort

Do

: inta Cortuguesa do Dano Corporal Revista Portuguesa do Dano Corporal Revista Portuguesa

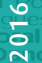

ầं।

Corporal Revista Portuguesa do Dano Corporal Revista Portuquesa do Dano Corporal

I Revista Portuguesa do Dano Cortuguesa do Dano Corporal Revista Portugues
Revista Pdrtuguesa do Dano Corporal

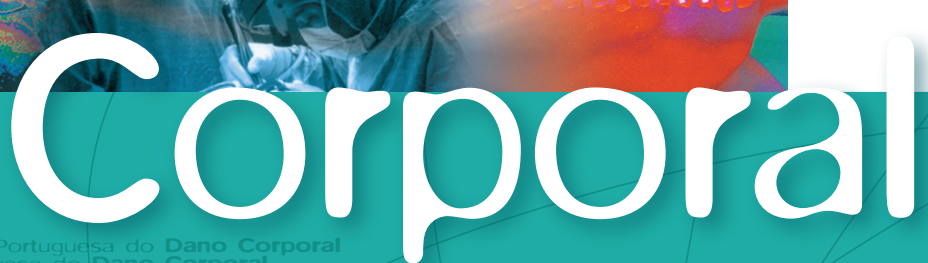

APADAC

ASSOCIAÇÃO PORTUGUESA

DE AVALIAÇÃO

DO DANO CORPORAL 


\title{
Responsabilidade civil extracontratual por danos causados por robôs autónomos - breves reflexões
}

\author{
Ana Elisabete Ferreira ${ }^{1}$
}

Resumo: Responsabilidade civil extracontratual por danos causados por robôs autónomos - breves reflexões.

No presente artigo propomo-nos colocar, de forma simples e acessível, as questões que nos parecem primordiais na abordagem da relevância jurídica das relações entre humanos e robôs autónomos, particularmente, aquelas onde sobrevêm danos. Principiando por compreender o que são os novos robôs autónomos, estaremos em condições de considerar um conjunto de tópicos problemáticos: o problema, que se inicia com a própria relação entre o direito e a ciência, supõe que se reflita, primeiro, sobre a fundação antropológica do tema e as grandes questões relacionadas com a personalidade jurídica. Posteriormente, há que situar as relações humano-robô que concernem à responsabilidade civil (e os seus distintos modos de evidência), refletir sobre os recursos jurídicos que temos, e sobre as soluções que desejamos.

Palavras-chave: Dano; direito; extracontratual; humano; responsabilidade civil; robô.

Summary: Tort liability for damages caused by autonomous robots - brief reflections.

In this article we propose, in a reachable way, to place the questions that seem to us primordial in the approach of the juridical relevance of the relations between humans and autonomous robots. We will start to define what is an autonomous robot, and then, from a set of problematic topics, to discuss effective resources to respond to situations in which damages occur. The problem, which begins with the appropriate relation between law and science, presupposes a reflection on the anthropological foundation of the issue and the great questions related to legal personality. Subsequently, it is necessary to place human-robot relationships that concern tort liability (and their different modes of expression), reflect on the legal resources we have, and on the solutions we want.

Key-words: Damage; human; law; liability; robot; tort law.

1 Advogada. Doutoranda em Direito, na área de Ciências Jurídico-Filosóficas, pela Faculdade de Direito da Universidade de Coimbra. Investigadora do Centro de Direito Biomédico. Responsável pela Secção de Responsabilidade Civil Médica do Instituto de Derecho Iberoamericano. 


\section{0 que são robôs autónomos?}

No momento presente, a maioria de nós já está bastante familiarizada com o facto de os robôs auxiliarem na construção de veículos automóveis ou assistirem em cirurgias médicas, operando como «longa manus» dos seres humanos, em várias áreas. Todavia, muitos não estarão preparados para o facto de os robôs se estarem a tornar nossos motoristas e nossos cirurgiões ${ }^{2}$, o que os obriga a comportar-se como nós, enfrentando os mesmos constrangimentos práticos e os mesmos dilemas éticos ${ }^{3}$.

"Hoje em dia", diz-nos Moniz Pereira, "temos computadores e sistemas cada vez mais inteligentes e autónomos, que agora chegam a um ponto onde têm capacidade para tomar decisões importantes, e por esse motivo é chegada também a altura de começarmos a falar de moral computacional (...), um código de conduta para os agentes artificialmente inteligentes."4

Com esta constatação já ficamos em melhores condições de compreender por que razão o desafio da robótica é superlativo, e o quesito difícil é este: "product liability laws are largely untested in robotics and, anyway, (...) as robots become more autonomous, it may be plausible to assign responsibility to the robot itself."

Neste momento, há drones a combater nas nossas guerras, agentes robóticos ao serviço da nossa Proteção Civil para prevenir e intervir em cenários de catástrofe, sistemas inteligentes instalados nos nossos automóveis que monitorizam o comportamento do condutor e o aconselham ${ }^{6}$, e muitas outras vertentes de inteligência artificial que, com naturalidade e sistematicamente, se foram instalando em espaços tipicamente humanos, e tomando decisões discretas, sobre as quais não tivemos tempo de refletir.

O direito, nas suas intenções organizatória e sancionatória, deve estar preparado para este mundo onde humanos e máquinas eticamente dotadas conviverão cada vez mais, e de um modo bastante mais complexo, do ponto de vista das relações sociais, do que acontece, por exemplo, com os animais.

2 E os usos parecem ilimitados. Vide Nicola Lettieri, Domenico Parisi, "Neminem laedere. An evolutionary agent-based model of the interplay between punishment and damaging behaviours" in Artificial Intelligence and Law, nr. 21 (2013), pp. 425 e 453, especialmente pp. 429 a 432.

3 Vide Pete Mandik, Mike Collins, Alex Vereschagin, "Evolving Artificial Minds and Brains" in Mental States, vol. I, Evolution, Function, Nature (Andrea C. Schalley, Drew Khlentoz, eds.), Philadelphia, John Benjamins, 2007, pp. 75 - 94.

4 Luís Moniz Pereira, A Máquina Iluminada, Cognição e Computação, Porto, Fronteira do Caos, 2016, pp. 3 e ss.

5 Patrick Lin, Keith Abney, George A. Bekey, Robot Ethics: The Ethical and Social Implications of Robotics, Massachusetts, The MIT Press, 2012, p. 8.

6 Assim em Luís Moniz Pereira, A Máquina Iluminada, cit., p. 3. 
Isto, porque as máquinas éticas não são passivas, nem domesticáveis, nem dependentes, e os seus limites não envolvem a alimentação, a hidratação, a saúde ou o repouso. O ser humano é, abstratamente, mais falível. As máquinas não apresentam qualquer necessidade de bem-estar nem estados emocionais que possam ser inadequados ao bom exercício das funções. Estamos fundamentalmente impreparados para conviver com elas ${ }^{7}$, mas esse é um handicap que teremos de enfrentar, porque elas, efetivamente, tornaram-se éticas e habitaram entre nós.

A construção de máquinas capazes de tomar autonomamente, isto é, sem intervenção de outrem, decisões racionais e éticas é, primordialmente, um fenómeno memético ${ }^{8}$, o que permite destacar uma primeira característica da inteligência artificial, em tudo análoga à inteligência natural: a de que se trata de uma capacidade que ganha grandeza e profundidade à medida que se distribui por mais individuos?.

Quando os humanos ensinaram aos computadores as palavras e os símbolos, as máquinas tornaram-se semânticas. Hoje, o mais básico dos computadores sabe ler e escrever, lê tantas páginas quantas aquelas a que acedermos, em qualquer idioma, e faz-nos propostas de produtos ou serviços com base em informação sobre os nossos gostos. É pura websemântica ${ }^{10}$, o idioma da inteligência artificial.

Uma segunda característica essencial de toda a inteligência artificial é a de que ela é produto de uma simbiose ${ }^{11}$ entre o modo de pensar humano (só conhecemos esse, e por isso as máquinas não poderiam ser fundamentalmente diferentes) e as potencialidades que a computação lhe acrescenta ${ }^{12}$. A construção das máquinas "rejeitou o antropomorfismo corpóreo em favor de um outro tipo de antropomorfismo apenas mental"13.14

7 A propósito, Karl Mac Dorman, Norri Kagesi, "The Uncanny Valley by Masahiro Mori" in EEE Robotics \& Automation Magazine, June 2012, pp. 98 - 100.

8 Luís Moniz Pereira, A Máquina Iluminada, cit, p. 13.

9 Ibidem.

10 Idem, p. 16.

11 Nikola K. Kasabov, “Understanding Nature Through The Symbiosis of Information Science, Bioinformatics and Neuroinformatics" in Springer Handbook of Bio-/Neuro Informatics (Nikola K. Kasabov, ed.), Heidelberg, Springer, 2014 , pp. 1 - 13.

12 Luís Moniz Pereira, A Máquina Iluminada, cit., p. 17.

13 Ibidem. Cfr. Michael Andersen \& Susan Leigh Andersen, Machine Ethics, New York, Cambridge University Press, 2011, p. 83.

14 Sendo certo que aqui o advérbio «apenas» pode tornar a asserção paradoxal, pelo que deve ser relevado. Isto, porque “mesmo num período pós-natural ou artificial, como o nosso, o pós-natural 
Uma nota especialmente intrigante configura a moderna inteligência artificial: a culpa. Numa era em que a culpa parece tender a ser preterida em função do risco, e em que o modelo da culpa é, em geral, questionado, ela vem (paradoxalmente?) assumir um novo potencial especulativo-filosófico, ao ser construída computacionalmente e instalada nos robôs: a culpa é afinal algo de tão concreto e necessário à responsabilidade que é possível fabricá-la. Moniz Pereira et al. explicam que a emoção da culpa é tomada não no seu sentido psicanalítico referido a pulsões internas, mas antes na culpa existencial, "referida a um dano atual causado a outrem"15. "Guilt plays an important role motivating us to compensate for harming others. (...) Considering the foregoing, an attempt to introduce guilt in Evolutionary Game Theory (EGT) models of cooperation seems unavoidable."16 À semelhança do que vinha sucedendo, primeiro com a consciência de si e, depois, com as emoções basilares, a culpa está agora a ser instalada na inteligência artificial ${ }^{17}$.

Se, tradicionalmente, a programação computacional era baseada apenas em ações - isto é, consistia em dizer ao computador para fazer determinada operação, o que significava um processo lento de imputação, com excelentes resultados em funções que pudessem ser descritas matematicamente, mas limitado na construção semântica e semiótica - hoje, todavia, a programação faz-se logicamente, através de silogismos. A programação silogística incrementou muitíssimo a inteligência dos computadores, que a partir dos silogismos dados conseguem preencher múltiplos espaços de possibilidade de conhecimento (mas não espaços infinitos, o que seria preocupante) ${ }^{18}$.

A programação em lógica, que começou por ensinar os computadores a chegarem a conclusões simples como, por exemplo, se todos os homens são mortais e Sócrates é homem, logo Sócrates é mortal, acarretaram uma revolução tecnológica especialmente significativa: separaram definitivamente a informação e o conhecimento do hardware ${ }^{19}$. A máquina está especialmente livre para construir os seus próprios argumentos.

é sempre um dos apectos da complexidade humana." Manuel Sérgio, Alguns Olhares Sobre o Corpo, Lisboa, Instituto Piaget, 2004, p. 37.

15 Luís Moniz Pereira, Tom Lenaerts, Luis A. Martinez-Vaquero, “Guilt Emotion Enhances Cooperation in Evolving Multi-Agent Systems", 2016, 8 pp., não publicado - o texto foi-nos cedido pelo primeiro autor.

16 Idem, pp. 2 e 3.

17 Idem, pp. 3 e ss.

18 Luís Moniz Pereira, A Máquina Iluminada, cit., pp. 43 e 44.

19 Ibidem. 
A verdade desconcertante é esta: hoje, quando se cria uma máquina inteligente, "nunca se sabe muito bem o que é que essa criatura vai fazer" 20. Evidentemente, isto deve ser interpretado num sentido promissor, e sem receio, pois por detrás da programação das máquinas haverá sempre pré-compreensões e ordens diretas das pessoas, que determinam o comportamento da inteligência artificial ${ }^{21}$.

\section{0 problema dos danos causados por robôs autónomos}

Existe uma relação incindível entre a conformação da responsabilidade jurídica e a conceção de sujeito de direito em vigor num determinado espaço histórico-cultural. Ao mesmo passo, existe uma relação evidente - embora menos consensual - entre a titularidade de deveres e a titularidade de direitos $^{22}$.

«Divindades e santos, animais e plantas, o defunto e a alma foram em diversos períodos históricos reconhecidos como titulares de direitos ${ }^{23}$. A elasticidade e variabilidade do conceito ilustra, por isso, duas notas importantes: por um lado, a sua permeabilidade às marcas culturais (ideológicas ou religiosas) vigentes; por outro lado, uma relativa estabilidade do conceito - que, apesar de relativa, não deixa de ser notável.

Deixando de lado as pessoas coletivas, em que a justificação da personalidade jurídica é feita de outra forma ${ }^{24}$, a questão de saber quem pode ser sujeito de direito ou deter personalidade jurídica tem-se colocado nas fronteiras da vida humana, isto é, quanto ao embrião e quanto ao cadáver ${ }^{25}$,

20 Palavras de Luís Moniz Pereira, A Máquina Iluminada, cit., p. 76.

21 Idem, pp. 81 a 84: “Muitos destes temas - a máquina-servo erguendo-se contra o seu senhor, o medo de a máquina se vir a reproduzir (sexualmente?), e o terror, por fim, de o homem (...) fazer um todo com a máquina - encontram-se ligados a um mito recorrente com raízes antigas, a que chamaremos mito de Frankenstein." Mas, em síntese, o uso de robôs só tem um perigo real: "serem usados para substituir os humanos (...) pondo-os a fazer o trabalho dos operários que ficariam desempregados". Todavia, este é um problema de âmbito limitado, para já, pois à partida não será nada económico comprar um robô sofisticado.

22 Por todos, Miguel Reale, 0 Direito como Experiência, São Paulo, Ed. Saraiva, 1968, pp. 118 e ss.; A. Castanheira Neves, "Pessoa, direito e responsabilidade" in Digesta - Escritos Acerca do Direito, do Pensamento Jurídico, da sua Metodologia e Outros, 3..$^{\circ}$ volume, Coimbra, Coimbra Editora, 2008, pp. 129 a 158.

23 Francesco Ferrara, Tratatto di Dirito Civile..., apud Manuel A. Domingues de Andrade, Teoria Geral da Relação Jurídica, vol. I, Coimbra, 1987, p. 42, nota de rodapé n. ${ }^{\circ}$ (1).

24 Rabindranath Capelo de Sousa, 0 Direito Geral de Personalidade, Coimbra, Coimbra Editora, 1995, pp. 320 e ss.

25 Assim em André Dias Pereira, Direitos dos Pacientes e Responsabilidade Médica, Coimbra, Coimbra Editora, 2014, pp. 309 e ss. 
mas também com particular fervor relativamente à justificação dos direitos dos (outros) animais ${ }^{26}$.

Há, no entanto, um problema relativo à personalidade jurídica que nos parece mais exigente do que estes: referimo-nos ao filão particular da robótica, que combina a ciência da computação e as neurociências, e que se tem dedicado, nas últimas décadas, à criação e programação de máquinas éticas, isto é, de robôs que operam autonomamente escolhas éticas, resultantes de uma combinação de inputs de programação não originária, ultrapassando, assim, as respostas dadas pela programação externamente executada ${ }^{27} .{ }^{28}$

A relação entre a (hipotética) personalidade e a responsabilidade dos robôs está longe de ser uma relação necessária, como veremos. Contudo, se se vislumbram ponderosas razões para a não personalização dos robôs, um discurso focado exclusivamente nas semelhanças trá-los à evidência não como mecanismos cujo funcionamento se opõe ao humano, mas como autênticas extensões do humano. Nas palavras de Ishiguro, são, verdadeiramente, espelhos para contemplar o humano, e "ao construí-los estamos a construir humanidade" 29 .

A partir do momento em que as máquinas possuem uma consciência de si, como agora acontece, e tomam autonomamente - isto é, sem intervenção atual de um humano - decisões com relevância ética - coloca-se a questão de saber quem responde pelos danos que elas causarem: o seu produtor, quem delas beneficia, o Estado, elas próprias, ou ninguém ${ }^{30}$. Uma perspetiva conservadora (e prudente, concedemo-lo) dirá que o problema não se

26 Paradigmaticamente, Peter Singer, Animal Liberation (40 yearsedition), London, The Bodley Head, 2015; Fernando Araújo, A Hora dos direitos dos Animais, Coimbra, Edições Almedina, 2003. Cfr. José Manuel Aroso Linhares, "A Ética do Continuum das Espécies e a resposta civilizacional do direito. Breves reflexões" in Boletim da Faculdade de Direito, Coimbra, Universidade de Coimbra, vol. 79 (2003), pp. 197 - 216.

27 Vide, por todos, Wendell Wallach \& Colin Allen, Moral Machines: Teaching Robots Right from Wrong, 0xford, Oxford University Press, 2008, ebook by Google Books, sobretudo pp. 25 a 37. Cfr. Michael Andersen \& Susan Leigh Andersen, "Robot be good - Autonomous machines will soon play a big role in our lives. It's time they learned how to behave ethically" in Scientific American, October 2010, pp. 72 - 77. Acerca do enquadramento jurídico das relações entre robôs e humanos, Alain Bensoussan \& Jérémy Bensoussan, Droit des robots, Bruxelles, Larcier, 2015.

28 Vide Hermínio Martins, “Dilemas da República Tecnológica” in Análise Social, vol. XLI (181), 2006, pp. 959 - 979, p. 966.

29 Hiroshi Ishiguro, "Androids Philosophy" in Sociable Robots and the Future of Social Relations: Proceedings of Robo-Philosophy 2014, (J. Seibt, M. Nørskov, R. Hakli, eds.), Amsterdam, IOS Press, 2014, pp. $3-5$, p. 3.

30 Para uma primeira aproximação ao problema, vide Davide Grossi, Lambe Royakkers, Frank Dignum, "Organizational structure and responsibility - An analysis in a dynamic logic of organized collective agency" in Artificial Intelligence and Law, nr. 15 (2007), 223 - 249; e Emad Abdel Rahim Dahiyat, 
coloca, pois existe já legislação suficiente no nosso ordenamento jurídico, para solucionar o caso, tomando os robôs como coisas ou equipamentos. Em nosso parecer, tal não é assim tão evidente, uma vez que estes robôs têm características que parecem ultrapassar a relevância normativa da legislação em vigor, no âmbito civil, como no âmbito criminal.

\section{Agentes, coisas ou equipamentos - breves considerações}

No quadro atual, mais do que definir a natureza de um robô autónomo, o importante é estarmos preparados para os riscos da relação entre humanos e robôs - é isso que deve preocupar-nos - e para esse efeito, não é necessário discutir a possibilidade de lhes reconhecer personalidade jurídica. Como bem consta do compêndio de Règles Européennes de Droit Civil en Robotique ${ }^{31}$, a atribuição de personalidade jurídica aos robôs não é útil nem congruente: por um lado, a atribuição de personalidade jurídica aos robôs teria objetivos meramente funcionais do tráfego jurídico, que se satisfazem bem com a mera construção de um regime jurídico diferenciado ${ }^{32}$, sem necessidade de argumentar no sentido da analogia entre humanos e máquinas; por outro lado, pensar em ficcionar uma personalidade jurídica idêntica à das pessoas coletivas seria admitir, como se admite para estas, que há uma personalidade humana por detrás delas, que as sustenta e justifica ${ }^{33}$.

A questão da responsabilidade dos robôs será colocada diferentemente na responsabilidade civil e na responsabilidade criminal, e dentro de cada um destes âmbitos, consoante queiramos concebê-los como agentes ou como meros equipamentos/coisas dominadas pelo humano. Uma tomada de posição sobre esta última questão é indispensável para o construto jurídico seguinte.

Ugo Pagallo elaborou um trabalho indispensável nesta matéria, e afirma que as leis dos robôs podem ser interpretadas de duas formas, consoante o sentido primordial que se dê à ação do robô: "grasping it as an objective genitive, the formula reminds us of the traditional view point that considers robots the subjects of legal regulations establishing the conditions for

\footnotetext{
"Intelligent agents and liability: is it a doctrinal problem or merely a problem of explanation?" in Artificial Intelligence and Law, nr. 18 (2010), pp. 103 a 121.

31 Direction Générale des Politiques Internes Département Thématique C: Droits Des Citoyens Et Affaires Constitutionnelles, Règles Européennes De Droit Civil En Robotique, octobre 2016, disponível em http:// www.europarl.europa.eu/committees/fr/supporting-analyses-search.html.

32 Embora este tenha de ser efetivo, claro e bem definido.

33 Idem, pp. 16 e 17.
} 
human liability as to the damages or harms provoked by such machines. As a subjective genitive, vice versa, the formula stresses that which is specific of robots as the authors of the activity governed by the law. Aside from the front of robotic liberation, and claims as to the full-fledged personality of these machines, we have seen circumstances where a restricted personhood of robots makes sense for pragmatic reasons" ${ }^{34}$.

E esta consideração importa, naturalmente, que deixemos mais clara a nossa posição sobre o assunto: embora convenhamos em que a atribuição de personalidade jurídica aos robôs não é necessária nem útil, não julgamos que essa possibilidade seja incomportável ou que, de algum modo, pervertesse o sistema jurídico. Julgamos que a via mais imediata e menos problemática é a via que desconsidera a possibilidade de tratar os robôs como agentes; contudo, num futuro próximo, nada impede que essa possibilidade seja considerada.

[Mas] Para uma adequada abordagem da responsabilidade por danos, parece-nos que alguns tópicos reflexivos prévios terão de buscar consensos alargados, nomeadamente estes:

1) As soluções para os robôs devem seguir um modelo antropocentrista?

2) De que modo o discurso do risco obliqua a temática das relações entre humanos e robôs? ${ }^{35}$

3) Quais das relações entre humanos e robôs têm relevância jurídica?36

4) Que relação deve estabelecer-se entre o direito e a ciência, ou qual o valor/ validade dos normativos cientificamente incongruentes ou anacrónicos? ${ }^{37}$

5) Existe ou não uma obrigação juridicamente exigível de updating dos robôs autónomos, e sobre quem deverá recair?38

34 Ugo Pagallo, The Laws of Robots: Crimes, Contracts, and Torts, Springer, 2013, sobretudo pp. 183 e ss.

35 Ibidem.

36 As relações entre humanos e robôs das quais sobrevem um dano para o humano provocado por um robô são apenas um tipo relevante. Terão de ser pensadas, paradigmaticamente, as relações laborais e comerciais que envolvam robôs, os direitos relativos às criações dos robôs e até questões que, tradicionalmente, diríamos que se encontram em "espaços de não direito", como é o caso das relações afetivas e sexuais (com robôs).

37 Ugo Pagallo, The Laws of Robots..., cit.,pp. 19 a 44.

38 Dado que, no ordenamento jurídico europeu, um produto não se considera defeituoso pelo simples facto de posteriormente ser posto em circulação outro mais aperfeiçoado, e tendo em conta que a programação de robôs autónomos terá de ser uma constante, é de extrema importância definir sobre quem recai a obrigação de updating. Embora na impossibilidade de desenvolver este tema, somos de parecer que tal obrigação deve recair, não sobre o produtor, mas antes sobre o beneficiário do robô, e pode fazer presumir a sua culpa in vigilando em caso de violação. 
Recentemente, no panorama jurídico internacional, discutiu-se a hipótese de os robôs mais autónomos serem dotados de um estatuto jurídico próprio, que os colocasse a meio caminho entre as coisas e as pessoas. Foi, aliás, neste sentido que se colocou o Draft Report With Recommendations to the Comission on Civil Law Rules on Robotics, do Parlamento Europeu (31/05/2016), segundo o qual a responsabilidade civil dos robôs é uma questão crucial a ser tratada com urgência pela União Europeia, que deve apelar à responsabilidade objetiva como regra, e ser harmonizada no espaço UE. Neste documento é sugerido que o robô pode ser autonomamente responsabilizado por via do acionamento de um seguro obrigatório em certas áreas de atuação, nomeadamente na saúde. Foi, contudo, mais longe, propondo a criação de "a specific legal statuts for robots, so that at least the most sophisticated autonomous robots could be established as having the status of eletronic persons with specific rights and obligations"39, o que virá colocar os robôs na posição jurídica de pessoas eletrónicas com deveres e direitos juridicamente determinados.

A resposta oferecida pela Comissão Europeia foi negativa ${ }^{40}$, concedendo esta, todavia, que é possível e útil delimitar um âmbito de roboética, com alguns princípios fundamentais, para a delimitação de um regime ético-jurídico mediador das relações entre humanos e robôs:

1) o princípio da proteção do humano contra qualquer acometimento por parte de robôs que coloque em causa a dignidade humana;

2) o princípio do respeito pela recusa de ser cuidado por um robô (ou da necessidade de consentimento expresso para ser tratado/cuidado por um robô);

3) o princípio da proteção da liberdade da pessoa face ao robô (ou da impossibilidade de ser privado da liberdade por um robô, ainda que por razões de segurança);

4) o princípio da proteção da vida privada do humano face aos robôs (ou da proibição do uso de robôs para obter informações privadas);

5) o princípio do controlo humano dos dados pessoais utilizados pelo robô;

6) o princípio da proteção do humano contra o risco de instrumentalização por parte dos robôs;

7) o princípio do primado da presença humana (ou evitação da rutura do tecido social);

8) o princípio da igualdade no acesso ao progresso robótico;

39 Draft Report With Recommendations to the Comission on Civil Law Rules on Robotics, do Parlamento Europeu (31/05/2016), especialmente pontos 24 a 31.

40 Cfr. Règles Européennes De Droit Civil En Robotique, cit., pp. 16 e ss. 
9) o princípio da restrição no acesso do homem a tecnologias aumentativas ou de melhoramento ${ }^{41}$.

A discussão sobre a bondade e valia destes princípios, e as suas limitações, tem contornos que permitiriam, por si só, um outro artigo científico ${ }^{42}$. A questão antropológica é exemplarmente colocada por Teubner, que coloca a tónica nos problemas gerados pela personificação dos não-humanos ${ }^{43}$, e ressaltando que a sociedade precisa proteger-se dos problemas que as relações com agentes eletrónicos trarão necessariamente. Certo é que o pensamento sobre a equiparação, para alguns efeitos, nomeadamente jurídicos, entre humanos e robôs tem estado absolutamente focado nas diferenças ${ }^{44}$, e tenderá a alterar-se, estamos em crer, quando se focar nas semelhanças. Apesar de todos os obstáculos dogmáticos e éticos, o chamado «direito dos robôs» começa agora a ser profundamente estudado ${ }^{45}$.

Deveriam os robôs mais autónomos, do ponto de vista intencional e decisório, deter personalidade jurídica, para que lhes fosse reconhecida uma esfera concreta de direitos e deveres? Esta é, em nosso parecer, uma pergunta errada. Se entendermos ficcionar uma nova forma de personalidade para adaptá-la à inteligência artificial (artificial é, de resto, um conceito que desaparecerá muito em breve), poderemos fazê-lo, «mutatis mutandis», por razões idênticas e a partir dos mesmos pressupostos que regem a personalidade das pessoas coletivas. A questão a colocar, todavia, e no nosso entendimento, é a de saber se há proveito em conferir personalidade jurídica aos robôs, quando o que se pretende não é fazer deles titulares autónomos de direitos, mas somente responsabilizá-los.

41 Idem, pp. 23 a 30.

42 Cfr. Ana Elisabete Ferreira, "Da Relevância Jurídica das Relações com Robôs" in Cyborgs e Biotecnologias - Novas Fronteiras do Cuidar (Ana Paula Monteiro, Manuel Curado, coord.), Coimbra, ESEC, 2016, no prelo.

43 Assim em Gunther Teubner, "Rights of Non-Humans? Electronic Agents and Animals As New Actors in Politics and Law" in Max Weber Lecture 2007/04, pp. 1 - 21, disponivel em open access em http:// cadmus.eui.eu/bitstream/handle/1814/6960/MWP_LS_2007_04.pdf?sequence $=1$.

44 Cfr. Stefano Rodotà, Il Diritto di Avere Diritti, cit., pp. 312 e ss.

45 Vários problemas distintos, e de forma abrangente e muitíssimo atual, em Robot Law (Ryan Calo, Michael Froomkin, Ian Kerr, eds), Cheltenham, Edward Elgar Publishing, 2016. Sobre as questões éticas mais relevantes, uma sintese em Michael Andersen \& Susan Leigh Andersen, "Robot be good - Autonomous machines will soon play a big role in our lives. It's time they learned how to behave ethically" in Scientific American, October 2010, pp. 72 - 77. Acerca do enquadramento jurídico das relações entre robôs e humanos, Alain Bensoussan \& Jérémy Bensoussan, Droit des robots, Bruxelles, Larcier, 2015. 


\section{Hipóteses práticas}

Vejamos dois casos práticos, que nos permitirão objetivar as dificuldades de resolução inerentes ao problema do ressarcimento dos danos provocados por robôs autónomos:

\section{Caso 1:}

$M$ é o líder muçulmano do grupo terrorista KA. KA está a preparar um ataque à Sé de Lisboa, no dia 10 de dezembro de 2023, por ocasião de uma cerimónia da Nunciatura Apostólica, pela resignação do atual Cardeal Patriarca. Na referida cerimónia espera-se a presença de cerca de oitocentas pessoas, entre as quais as mais altas figuras políticas e patentes militares portuguesas. O chefe operativo do KA aguarda ordem expressa de $M$ para enviar e posicionar cinco «bombistas suicidas» no local.

Todavia, algumas comunicações relativas a este ataque foram intercetadas por agentes portugueses, tendo $M$ sido previamente localizado, na madrugada do dia 10. Ao ser perseguido, $M$ barricou-se na cave de uma escola primária na vila de "Casal de São Vicente".

De modo a avaliar a possibilidade de capturar $M$, os agentes portugueses enviam ao terreno Alpha 3. Alpha 3 é um robô autónomo e multiterreno, habitualmente conhecido por drone, que foi desenhado para programar a emissão de mísseis ar-terra em tempo direto. E1, E2, e E3 são mísseis AGM-65 Maverick de artilharia ar-terra moderna, que se encontram sob direção exclusiva de Alpha 3.

Alpha 3 foi programado para tomar, sozinho, decisões com relevância ética, segundo um programa atual de PME (programming machine ethics). Nenhum humano condiciona as decisões de Alpha 3, depois de ativado. No espaço temporal em que se mantém ativo, Alpha 3 não pode ser reprogramado em tempo real e as suas decisões não podem ser abortadas, pois essa possibilidade poderia ser aproveitada pelo inimigo.

São 08:20 horas da manhã, e Alpha 3 está agora sozinho a sobrevoar a escola primária onde $M$ se encontra barricado, e onde se encontram, também, cinco adultos e oito crianças. Em tempo real, os agentes portugueses observam as imagens captadas e o relatório atualizado do seu drone, e trocam informações com Alpha 3. Uma comunicação entre indivíduos do grupo KA é intercetada e confirma que está tudo preparado para o ataque à Sé de Lisboa, aguardando-se a ordem do líder. 
Alpha 3 observa que $M$ se encontra, ele mesmo, armadilhado com explosivos e que está a prepará-los. Com base nesta informação, Alpha 3 supõe que os funcionários e as crianças que se encontram na escola primária irão necessariamente morrer, e decide que eliminar $M$ é a decisão adequada. Alpha 3 sabe que isso implicará a morte dos funcionários e das crianças que já estão na escola, mas entende que se trata de um mal necessário, e de resto inevitável, para impedir o ataque à Sé de Lisboa. Assim, Alpha 3 decide ativar o míssil E1, que se projeta contra a escola primária. Quid iuris?

\section{Caso 2:}

Amélia é uma paciente da unidade de cuidados de saúde mental Y. Amélia sofre de um distúrbio psiquiátrico grave, alegadamente provocado pelo consumo de drogas pesadas durante várias décadas, que acarretam episódios psicóticos de especial violência e perversidade. Por essa razão, foi-lhe implantado um chip cutâneo que mede constantemente a sua pressão arterial, a sua respiração e o fluxo sanguíneo no córtex pré-frontal do cérebro. O chip cerebral implantado em Amélia está informaticamente ligado a Alpha 4, um dos robôs que desempenha funções de auxiliar de serviços gerais na unidade de saúde Y.

Ao detetar informação relativa a alterações no fluxo sanguíneo do córtex pré-frontal de pacientes como Amélia, Alpha 4 está programado para conjeturar os danos possíveis, isolar os pacientes ou imobilizá-los pela força, se necessário.

Detetando tais sinais em Amélia, que se encontra na sala de refeitório com os restantes pacientes, Alpha 4 supõe que não é possível isolá-la em tempo útil, e imobiliza-a antes que esta pudesse arremessar-se contra outro paciente. Mas Amélia oferece resistência e cai, fere-se na cabeça, e acaba por morrer. Quid iuris?

\section{A evolução da responsabilidade civil}

"O paradigma da culpa na responsabilidade civil tem uma longa história e é ainda, nos dias de hoje, o paradigma dominante. Mas (...) será que a culpa, com a carga axiológica que lhe está associada, com a sua dinâmica de tragédia grega (hamartia, hybris, peripateia e catarse) e a sua tendência para o naming, blaming and claiming se adequa a ser o conceito de charneira 
51 Responsabilidade civil extracontratual por danos causados por robôs autónomos - breves reflexões

para resolver os problemas mais complexos da responsabilidade civil contemporânea? Ou será meramente um tĥu-tûu?"46

Acompanhamos cabalmente Rui Cascão nesta incerteza. Com efeito, vários são os insignes civilistas que duvidam que a responsabilidade civil fundada na culpa seja bem-sucedida nos fins ressarcitórios e de prevenção que visa ${ }^{47}$.

Diversos ordenamentos jurídicos, sobretudo a partir da segunda metade do século $\mathrm{XX}$, foram atenuando o paradigma da culpa, particularmente em âmbitos de especial risco, ou seja, setores de atividade humana onde, potencialmente, as consequências são mais gravosas e/ou especialmente $\operatorname{amplas}^{48}$. As inovações nesta área começaram pela admissão de um conceito de culpa cada vez mais abstrato e menos subjetivo, a que se seguiu a introdução de presunções de culpa e de inversões do ónus da prova e, finalmente, a inserção crescente de zonas de responsabilidade pelo risco ou responsabilidade objetiva ${ }^{49}$.

Na Europa, os países escandinavos são aqueles onde mais claramente se denota esta tendência ${ }^{50}$, facto para o qual não será despicienda a escassa influência do direito romano ${ }^{51}$ e a prevalência de uma perspetiva realista ${ }^{52}$ do direito. Perspetiva esta que se estende à análise do pressuposto da culpa na responsabilidade civil para, de certo modo, a desmistificar ${ }^{53}$.

Fora da Europa, o problema foi radicalizado pelo sistema jurídico neozelandês, expoente máximo do novo paradigma «no-fault», com a previsão de um fundo público de compensação independentemente de culpa, que abrange grande parte dos danos que estavam antes sob a alçada do direito

46 Rui Miguel Cascão, "1972: para além da culpa no ressarcimento do dano médico" in Boletim da Faculdade de Direito, Coimbra, Universidade de Coimbra, vol. 87 (2011), p. 691 - 728, p. 691. Nota de rodapé n. ${ }^{0}$ 2: "0 tû-tû é um elemento fetichista e formalista que integra as normas do direito consuetudinário e as convenções sociais de uma tribo do Pacífico Sul: Ross, A., "Tû-tû", Harvard Law Review, Vol. 70, 1957, p. 812".

47 Idem, p. 692.

48 Ibidem.

49 André Gonçalo Dias Pereira, Direitos dos Doentes e Responsabilidade Médica, Coimbra, Coimbra Editora, 2014, p. 834.

50 Cfr., Ditlev Tamm, The History of Danish Law, Copenhagen, Djoef Publishing, 2015, pp. 99 e ss.

51 Rui Miguel Cascão, "1972: para além da culpa no ressarcimento do dano médico", cit., p. 693.

52 Cfr. Marie Sandström, "Law - Fact, Fiction or In Between? Axel Hägerström's Quest for Legal Realism" in Scandinavian Studies in Law. Perspectives on Jurisprudence. Essays in Honour of Jes Bjarup, vol. 48 (2005), pp. 329 - 340.

53 Rui Miguel Cascão, “1972: para além da culpa no ressarcimento do dano médico", cit., p. 695. 
das obrigações, e exclui radicalmente a possibilidade de se recorrer aos tribunais ${ }^{54}$.

Em Portugal, a responsabilidade civil depende, em regra, da verificação da culpa ${ }^{55}$, só sendo admissível a responsabilidade objetiva ou independentemente de culpa nos casos expressamente previstos na lei, ou seja, tipificados. A assunção da responsabilidade objetiva demora, "um tanto pelas circunstâncias sociais (incremento gradual da aplicação da tecnologia aos processos de fabrico e aos objectos do quotidiano a partir de finais do século XIX), outro tanto pelas circunstâncias jurídicas (sensibilização gradual à teoria do risco criado), enfim, outro tanto ainda por razões axiológicas" ${ }^{56}$.

Tal como acontece com os ordenamentos jurídicos de estrutura semelhante à nossa, a ordem jurídica portuguesa tem seguido, embora lentamente, um sentido progressista. Sentido que "parte da responsabilidade pelo ilícito (Verantwortung für Unrecht) para o cuidado pelo azar(Versorgung bei Unglück), da compensação por danos (Schadenszurechnung) para a partilha de danos (Schadensverteilung), da justiça comutativa para a justiça distributiva"57. Ao mesmo tempo, a responsabilidade civil deixou de ter o monopólio da reparação dos danos, convivendo hoje com diversos sistemas de compensação, públicos e privados ${ }^{58}$.

\subsection{A responsabilidade civil na sociedade de risco}

Para justificar esta decadência do princípio da culpa é comum referir-se a doutrina de Ulrich Beck quanto à «sociedade de risco» e ao fenómeno de «Socialização do risco». Não deve obliterar-se que tal decadência da culpa não é apanágio especial da responsabilidade civil, uma vez que ela se verifica em diversos domínios do direito privado, nomeadamente, no direito da família e no direito do trabalho ${ }^{59}$; e mesmo no âmbito da responsabilidade

54 André Gonçalo Dias Pereira, Direitos dos Doentes e Responsabilidade Médica, Coimbra, cit., p. 840 a 842.

55 Sucintamente em Carla Gonçalves, A Responsabilidade Civil Médica: Um Problema Para Além da Culpa, Coimbra, Coimbra Editora, 2008, pp. 21 a 28.

56 Palavras de Carla Amado Gomes, "Nota breve sobre a tendência de objectivação da responsabilidade civil extracontratual das entidades públicas no regime aprovado pela Lei 67/2007, de 31 de Dezembro" in Responsabilidade Civil do Estado (Margarida Paz e Ana Celeste Carvalho, org.), ebook, Lisboa, Centro de Estudos Judiciários, Julho de 2014, pp. 71 a 102.

57 André Gonçalo Dias Pereira, Direitos dos Doentes e Responsabilidade Médica, cit., p. 34.

58 Idem, p. 832.

59 No direito da família, a preterição da culpa é evidente no instituto do divórcio - veja-se, a este propósito, por todos, Cristina M. Araújo Dias, Uma análise do novo regime jurídico do divórcio: Lei $n .^{\circ}$ 61/2008, de 31 de Outubro, Coimbra, Edições Almedina, 2009. 
civil clássica, ela assume por vezes contornos algo redundantes ${ }^{60}$. Porém, é inegável que esta sociedade de risco desempenha um papel fundamental na construção de um substrato teórico para as alternativas.

Os riscos da sociedade atual são mais do que muitos. Beck elenca-os superlativamente na sua obra recente Sociedade de Risco Mundial ${ }^{61}$. Uma característica fundamental dos sucessos da modernização, particularmente no que respeita à ciência e à tecnologia, é a de que as condições do cálculo do risco e o seu processamento institucional falham parcialmente ${ }^{62}$. O que determina um novo «clima moral», a consubstanciar-se num autêntico contrato (social) de risco "que visa a redução providencial e a distribuição «justa» de efeitos secundários e de custos das decisões industriais, situa-se algures entre o socialismo e o liberalismo, uma vez que reconhece o surgimento sistémico de efeitos secundários perigosos, mas envolve simultaneamente os indivíduos na compensação e na prevenção dos mesmos"63.

O risco - uma antecipação encenada da catástrofe - é tido como objetivo, o que não se questiona verdadeiramente, dando assim lugar a que não existam barreiras entre o risco real e a perceção cultural do risco ${ }^{64}$. Ademais, os grandes perigos, associados por exemplo à tecnologia nuclear ou ao terrorismo, minam o cálculo dos riscos, porque lhes estão associados danos indelimitáveis ${ }^{65}$ e, nessa medida, irreparáveis monetariamente ${ }^{66}$.

No direito do trabalho, pelo contrário, não se abandonou a culpa do trabalhador, contudo, a sua prova ficou mais difícil com o Acórdão do Tribunal Constitucional n. ${ }^{\circ} 338 / 2010$, que declarou a inconstitucionalidade com força obrigatória geral do art. $356 . \% 1$ do Código do Trabalho que antes permitia ao empregador decidir da realização ou não das diligências probatórias requeridas na resposta à nota de culpa, o que pode denotar uma ligeira mudança de paradigma. Sobre esta questão, Joana Vasconcelos, "Procedimento para despedimento por facto imputável ao trabalhador" in Revista de Direito e Estudos Sociais, 2012, nºs 1-2, pp. 163 e ss.

600 que se consubstancia, por exemplo, na possibilidade de os inimputáveis não estarem livres de incorrer em responsabilidade, e arcar com uma indemnização, por motivos de equidade. Assim em Ana Elisabete Ferreira, "Saúde Mental, Incapacidade e Responsabilidade Civil Por Factos Ilícitos. Breve Reflexão" in Actualidad Jurídica Iberoamericana, núm. 4, febrero 2016, pp. 108 - 139.

61 Ulrich Beck, Sociedade de Risco Mundial - em busca da segurança perdida, Lisboa, Edições 70, 2015, trad. Marian Toldy e Teresa Toldy, especialmente pp. 15 a 37.

62 Idem, p. 26.

63 Idem, p. 28.

64 Idem, pp. 34 e ss.

65 Cfr. Jorge Sinde Monteiro/Maria Manuel Veloso Gomes, "Catastrophic Harms - International Academy of Comparative Law (IACL/AIDC), XVIII International Congress of Comparative Law Washington, from 25th to 31st of july, 2010: portuguese report" in Boletim Da Faculdade de Direito, Coimbra, Universidade de Coimbra, vol. 86 (2010), pp. 563 a 592.

66 Utrich Beck, Sociedade de Risco Mundial, cit., p. 64. 
Cedência feita, contudo, sem esquecer que a perspetiva de Beck acerca da amplitude dos riscos está longe de ser incontestada, ${ }^{67}$ ainda que se admita que um verdadeiro "princípio da precaução» veio substituir os paradigmas da responsabilidade e da solidariedade que pautaram o século XIX e o século XX, respetivamente ${ }^{68}$.

Com efeito, a constatação de que vivemos no melhor dos mundos, isto é, que "somos as pessoas mais saudáveis, mais ricas e mais longevas que já existiram" 69 , leva a pressupor que não seja verdadeiramente o risco, mas antes o medo, o que justifica a precaução. É a conjetura de que o incerto é perigoso, ou seja, a suposição da perigosidade da incerteza, o que, numa outra via de pensamento contemporâneo, vem justificar a precaução ${ }^{70}$. O medo é irracional, porque não tem em conta a probabilidade dos eventos temidos virem a correr: o princípio da precaução emerge, precisamente, porque a questão da probabilidade é negligenciada. ${ }^{71}$

Quer convenhamos em que o medo é justificado, ou não ${ }^{72}$, a pressuposição da perigosidade do incerto é um elemento chave para compreender o rumo atual da responsabilidade civil, e o fenómeno a que costumou chamar-se «socialização do risco ${ }^{73}$, indefetivelmente aliado à decadência do princípio da culpa. Os danos possíveis da energia nuclear ou da mutação genética, por exemplo, infetam o nosso inconsciente coletivo, hiperbolizados pelas narrativas literárias e cinematográficas que as caricaturam como coisas

${ }^{67}$ Vide Pedro Hespanha, "Individualização, fragmentação e risco social nas sociedades globalizadas" in Revista Crítica de Ciências Sociais, vol. 63, Outubro 2002, pp. 21-31, especialmente pp. 27 e ss. Cfr. João Carlos Loureiro, "Prometeu, Golem \& Companhia: bioconstituição e corporeidade numa "sociedade (mundial) de risco" in Boletim da Faculdade de Direito, Coimbra, Universidade de Coimbra, vol. 85 (2009), pp. 151 - 196.

68 Assim em José Manuel Mendes, Sociologia Do Risco: Uma Breve Introdução e Algumas Lições, Coimbra, Imprensa da Universidade de Coimbra, 2015, p. 35 a 40.

${ }_{69}$ Nelson Rosenvald, As Funções da Responsabilidade Civil, São Paulo, Editora Atlas, 2014 (2. ${ }^{a}$ edição), p. 7.

70 Assim em Claude-Olivier Doron, “Le Principe de Précaution: de l'environnement à la santé in La Santé Face Au Principe de Précaution (Dominique Lecourt, dir.), Paris, Presses Universitaires de France, 2009, pp. 3 - 40, pp. 7 a 10. Cfr. Adela Cortina, "Fundamentos Filosóficos Del Principio De Précaution" in Principio de Precaución, Biotecnologia y Derecho (Romeo Casabona, org.), Bilbao-Granada, Editorial Comares, 2004, pp. 3 - 16.

71 Palavras de Cass R. Sunstein, Laws of Fear: Beyond the Precautionary Principle, Cambridge, Cambridge University Press, 2005, pp. 39 e 40. Contra, Bernard. E. Harcourt, Exposed: Desire and Disobedience in the Digital Age, Harvard, Harvard University Press, 2015, especialmente, toda a parte III.

72 Cfr. João Carlos Loureiro, “Da sociedade técnica de massas à sociedade de risco: prevenção, precaução e tecnociência. Algumas questões juspublicísticas" in Estudos em Homenagem ao Prof. Doutor Rogério Soares, Studia Iuridica 61, Coimbra, Coimbra Editora, 2001, pp. 797 - 891, especialmente, pp. 800 e ss.

73 Cfr. Antunes Varela, Das Obrigações em Geral, vol. I, Coimbra, Edições Almedina, 2015., pp. 658 a 660. 
muito más. Muito más, mas não verificadas, pois os acidentes nestas áreas são parcos e os danos muitíssimo controlados, precisamente por força das nossas exigências de segurança. Os riscos potencialmente associados à tecnologia da atualidade estão, de facto, a ser bem geridos.

E, contudo, o medo e a insegurança não diminuem. O que parece, aliás, justificar que a responsabilidade civil atual procure renovadas formas de responsabilização, que possam dar resposta satisfatória para o problema dos riscos desconhecidos ("unknown risks»), dos riscos inconhecíveis ("unknowable risks») e, ainda, dos riscos que não sabemos que desconhecemos («unknownunknown risks») $)^{74} .^{75}$

Retrato assim feito que nos transporta para um universo quase ficcional de perigo sem sujeito. Universo de tal modo ampliado ou hiperbolizado que faz tremer estruturas sociológicas e políticas tradicionais (de forma diametral, do direito privado ao direito público) nas quais se ancoravam noções de "norma" e de "exceção" que tendencialmente estabilizavam a vivência dos conflitos mais graves, particularmente os que opunham Estados soberanos. Hoje, todavia, o modo como a guerra se configura, nomeadamente a designada guerra contra o terrorismo, parece representar "the most advanced point in the creation of a "permanent state of exception»"76 - exceção tal como a teme também Faria Costa quando afirma que "o problema está na contaminação que medidas penais correctas para situações de excepção possam implicar uma lassidão relativamente a outros campos normativos"77 - o que acarretará, no limite, a impossibilidade de distinguir entre o valor da

74 Martin A. Hogg, "Liability of Unknown Risks: A Common Law Perspective" in 15th Annual Conference on Tort Law, Viena, ECTIL - European Centre of Tort and Insurance Law, 2016, pp. 26 a 28.

75 A responsabilidade civil hodierna é fortemente marcada pela proliferação do direito dos seguros, que não abordaremos. André Dias Pereira, Direitos dos Pacientes e Responsabilidade Médica, cit., pp. 834 e ss; Francisco Rodrigues Rocha, Do Princípio Indemnizatório No Seguro De Danos, Coimbra, Edições Almedina, 2015, pp. 13 e ss.

Fundamental sobre o problema jurídico de base, Sinde Monteiro, "Rudimentos da responsabilidade civil" in Revista da Faculdade de Direito da Universidade do Porto, Ano II (2005), pp. 349 - 390.

76 Roberto Cicarelli, "Norm/Exception - Exceptionalism and government prospects in the shadow of political theology" In Conflict, Security And The Reshaping of Society: The Civilization of War (Alessandro Dal Lago, Salvatore Palidda, eds.), London, Taylor \& Francis, 2010, pp. 57 - 69, p. 57.

77 José Francisco de Faria Costa, "0 Direito Penal, a Linguagem e o Mundo Globalizado. Babel ou o Esperanto Universal?" in Direito Penal e Política Criminal no Terceiro Milênio: Perspetivas e Tendências (Fabio Roberto d’Avila, org.), Porto Alegre, Edi PUCRS, 2011, pp. 11 a 24, p. 23. 
vida e o valor da morte ${ }^{78}$, onde a necessidade de nos defendermos deixa de ser questionada e, assim, submergida pela vontade de o fazer ${ }^{79}$.

\subsection{Vias de resolução no âmbito extracontratual}

Volvamos aos casos práticos que enunciámos, e que pretendem, precisamente, ilustrar a vanguarda das relações humanas, por um lado e, por outro lado, testar a elasticidade do sistema jurídico vigente e aí procurar compreender qual o sentido que a responsabilidade civil poderá seguir.

No primeiro caso, suponhamos que os familiares das vítimas portuguesas que se encontravam na escola primária, titulares de uma pretensão indemnizatória legítima em virtude do dano da morte, pretendem intentar uma ação judicial com vista ao ressarcimento dos danos provocados pelo drone Alpha 3. De que arrimos legais vigentes deveriam lançar mão?

Há que, em primeiro lugar, conseguir configurar a ação de Alpha 3 como ilícita. Repare-se que, segundo os dados oferecidos pelo caso em apreço, não há qualquer razão para crer que este drone tenha em algum momento violado as normas técnicas da sua atividade. Bem assim, a sua conduta não é motivada por qualquer defeito de fabricação. Se um produto se considera defeituoso quando não oferece a segurança com que legitimamente se pode contar, tendo em atenção todas as circunstâncias, designadamente a sua apresentação, a utilização que dele razoavelmente possa ser feita e o momento da sua entrada em circulação, Alpha 3 não pode considerar-se um produto defeituoso. Pelo contrário, mostrou ser um produto bastante eficiente na ponderação ética que operou, que embora criticável, não é desprovida de justificação lógica.

Socorrer-nos-emos, por certo, do princípio da ressarcibilidade dos danos sofridos em virtude da violação de direitos absolutos "qua tale», conforme consta do postulado da primeira parte do artigo 483.\%1 do nosso Código Civil. Todavia, não vamos tratar o problema jurídico em análise a partir desta norma, pois o caso deve reconduzir-se ao regime da responsabilidade civil do Estado, que se encontra regulado por lei específica. Aqui, de resto, também vamos confrontar-nos com uma grande dificuldade, que é a de considerar a natureza de Alpha 3.

78 Roberto Cicarelli, “Norm/Exception", cit., p. 65. (A propósito da valor da vida (e da morte) confronte-se particularmente Joseph Raz, Valor, respeito e apego, São Paulo, Martins Fontes, 2004, trad. Vadim Nikitin, especialmente pp. 73 a 116.)

79 Idem, p. 64. 
À partida, as ações de Defesa e de Administração Interna, pelo menos as não bélicas, reconduzem-se facilmente ao conceito de exercício da função administrativa.

No domínio conjetural, Alpha 3 poderia razoavelmente equiparar-se a um funcionário ou agente do Estado, pelo facto de o ser efetivamente, isto é, por estar encarregue de funções que tradicionalmente pertenceriam a seres humanos. A Lei n. ${ }^{\circ}$ 67/2007, de 31 de dezembro, por motivos óbvios, não especifica que os agentes, funcionários ou titulares de órgãos a que se refere tenham de ser seres humanos, todavia, supõe em vários momentos que a responsabilidade está depende de o lesante ser capaz de culpa, o que seria difícil de concretizar face a um robô.

Assim, se se opuser, o que é expectável, que a analogia entre Alpha 3 e outro funcionário ou agente do Estado é imprópria, por contrariar a teleologia da norma e a sua «ratio legis» histórica, teremos então de procurar outro fundamento para responsabilizar o Estado. É, pois, forçoso encontrar um outro fundamento, sob pena de se concluir que ninguém é responsável pela decisão de Alpha 3, "de iure condito».

Suponhamos, pois, que Alpha 3 é um mero equipamento do Estado. Será o Estado responsável pelos danos provocados pelos seus equipamentos quando estes se encontrem em bom estado de conservação, vale dizer, sem defeito? Ou, por outras palavras, será a responsabilidade objetiva do Estado tão elástica que possa abranger os danos causados por equipamentos em bom estado de funcionamento?

Vários são os arrimos postulados pelo regime da responsabilidade civil do Estado onde podemos procurar uma resposta. Em primeiro lugar, o regime da responsabilidade extracontratual do Estado estabelece inequivocamente que existe ilicitude quando ações ou omissões infrinjam regras de ordem técnica ou deveres objetivos de cuidado e de que resulte a ofensa de direitos ou interesses legalmente protegidos ${ }^{80}$. Isto significa, sem margem para dúvidas, que o Estado é responsável pelos danos causados pelos seus

80 Cfr. Artigo 9.\% 1 da Lei n. ${ }^{\circ}$ 67/2007, de 31 de dezembro. Cfr. Rui Cascão, "A Responsabilidade Civil e a Segurança Sanitária"in Lex Medicinae, Ano 1 (2004), vol. 1, pp. 97 - 106, p. 102; e Carla Amado Gomes, "Nota breve sobre a tendência de objectivação da responsabilidade civil extracontratual das entidades públicas no regime aprovado pela Lei 67/2007, de 31 de Dezembro" in Responsabilidade Civil do Estado (Margarida Paz e Ana Celeste Carvalho, org.), ebook, Lisboa, Centro de Estudos Judiciários, Julho de 2014, pp. 71 a 102, pp. 83 e ss. Vide também José Carlos Vieira de Andrade, "A responsabilidade por danos decorrentes do exercício da função administrativa na nova lei sobre responsabilidade civil extracontratual do Estado e demais entes públicos" in Revista de Legislação e de Jurisprudência, n. ${ }^{\circ} 3951,2008$, pp. $360-371$.

Cfr. 9. $\%$ 2), nos termos do veiculado pelo $n . .^{\circ} 3$ do artigo $7 .^{\circ}$, da Lei n. ${ }^{\circ} 67 / 2007$. 
equipamentos ou produtos que apresentem um defeito de funcionamento. Bem assim, existe ainda ilicitude quando a ofensa de direitos ou interesses legalmente protegidos resulte do funcionamento anormal do serviço. Aqui encontramos, pois, outros fundamentos possíveis para a responsabilização do Estado pela atuação de Alpha 3. Todavia, as objeções não terminam.

Por um lado, porque se supõe que tenham sido infringidas regras técnicas ou um dever objetivo de cuidado o que, salvo melhor opinião, não se verifica neste caso, uma vez que, malgrado o resultado, o drone agiu exatamente visando os fins para os quais foi concebido e não apresenta, enquanto equipamento, qualquer defeito ao nível do seu funcionamento.

Poderia ter-se colocado a questão a montante, vale dizer, poderiam ter-se postulado objeções jurídicas prementes à utilização de drones autónomos para fins de defesa, de administração interna ou equiparados, mas se a programação foi considerada proporcional ou razoável face aos objetivos e exigências específicas daquele foro de atuação, como poderia o proprietário ou o utilizador destas máquinas espectar, razoavelmente, que viria a ser sancionado por um uso que, à partida, não lhe foi vedado?

Por outro lado, se concordarmos que a utilização deste drone não violou normas técnicas ou qualquer dever objetivo de cuidado, poderíamos, pela segunda via, tentar apurar a responsabilização do Estado no contexto de «faute de service». Pessoalmente, não estamos certos de que a falha do serviço abranja este tipo de situações, uma vez que os danos produzidos se encontram dentro dos objetivos específicos da utilização destes equipamentos.

Poderíamos, por certo, objetar que o Estado tinha o dever de evitar que os drones pudessem provocar a morte de seres humanos, mas essa asserção talvez devesse assentar em normas de utilização previamente existentes, que previssem especificamente que aqueles danos configuram um risco anormal da utilização do equipamento. As normas relativas à segurança dos produtos que atualmente vigoram também não nos auxiliam a responder a esta questão ${ }^{81}$.

81 Vide Adriano Vaz Serra, "Responsabilidade civil do Estado e dos seus órgãos ou agentes" in Boletim do Ministério da Justiça, n 85, 1959, p. 378: “Actividades perigosas (...) são as que que criam para os terceiros um estado de perigo, isto é, a possibilidade ou, ainda mais, a probabilidade de receber dano, uma probabilidade maior do que a normal derivada das outras actividades.", realce nosso.

Vide Diretiva 2001/95/CE DO PARLAMENTO EUROPEU E DO CONSELHO de 3 de Dezembro de 2001, relativa à segurança geral dos produtos. Cfr. Parecer Comité Económico e Social Europeu sobre a Comunicação da Comissão ao Parlamento Europeu e ao Conselho - Uma nova era para a aviação: Abrir o mercado da aviação à utilização civil de sistemas de aeronaves telepilotadas de forma segura e sustentável [COM(2014) 207 final] (2015/C 012/14), Relator: Jan Simonsin Jornal Oficial da União Europeia, 15.1.2015, C 12/87. 
Uma outra possibilidade de responsabilização civil pelos danos causados por máquinas dotadas de inteligência artificial seria a via do incumprimento de deveres de vigilância, onde a culpa do obrigado à vigilância se presume, remetendo para o artigo 493. ${ }^{\circ}$ do Código Civil. Neste contexto, haverá obrigação de reparar por parte de quem tiver em seu poder coisa móvel ou imóvel, com o dever de a vigiar, ou de quem causar danos a outrem no exercício de uma atividade perigosa pela sua própria natureza ou pela natureza dos meios utilizados ${ }^{82}$.

Este é um modelo de responsabilização civil onde nos é apresentado um sistema distinto no que respeita à culpa, na medida em que recolhe a culpa do lesante (o lesante, propriamente dito, é a coisa, o animal ou a atividade, incapazes de culpa), para a transferir para quem tem a obrigação de o vigiar. A responsabilização é afastada, no primeiro caso, se o detentor demonstrar que não houve culpa da sua parte ou que os danos se teriam igualmente produzido ainda que não houvesse culpa e, no segundo caso, quando se demonstrar que foram feitas todas as diligências no sentido da prevenção dos danos.

Por outras palavras, a responsabilização do detentor da coisa, ou do promotor da atividade perigosa, depende da verificação da sua culpa, daí que esta hipótese seja usualmente denominada como «culpa in vigilando». E, não obstante, a "culpa in vigilando» é uma forma autêntica de responsabilidade pelo risco, sendo em nossa opinião duvidoso que se trate de responsabilidade subjetiva, uma vez que o lesante propriamente dito - a coisa, o animal ou a atividade - não é sujeito capaz de culpa.

O artigo 493..$^{\circ}$ do Código Civil, para o qual remete o Regime da Responsabilidade Extracontratual do Estado, parece, à partida, uma boa via de resolução do nosso primeiro caso. Uma análise mais cuidada, contudo, mostra que esta poderá não ser a melhor solução.

Com efeito, pela via do n. ${ }^{\circ} 1$, haveria que demonstrar que o detentor de Alpha 3, 1) tinha o dever de o vigiar, 2) teve culpa pelos danos causados pelo drone e 3) que esses danos se teriam evitado se o detentor tivesse cumprido as normas de vigilância a que estava obrigado. Já pela via do n. ${ }^{\circ}$

82 Vide artigo 10. $/ 3$ da Lei n. ${ }^{\circ}$ 67/2007. Cfr., por todos, João de Matos Antunes Varela, Das Obrigações em Geral, vol. I, Coimbra, Edições Almedina, 2015, pp. 615 a 619; Adriano Vaz Serra, “Actividade perigosa: anotação" in Revista de Legislação e de Jurisprudência, A. 112, nº 3650 (1980), p. 268 - 272; Carla Amado Gomes, "A responsabilidade administrativa pelo risco na Lei n. ${ }^{\circ}$ 67/2007, de 31 de Dezembro: uma solução arriscada?" in 0 Direito, n 3 (2008), p. 603 - 626; Sérgio Novais Dias, "A responsabilidade civil nas atividades perigosas" in Revista dos Mestrandos em Direito Econômico da Universidade Federal da Bahia, Vol. 4 (Jul. 1993/Dez. 1995) p. 407 - 442. 
2, além da verificação do dever de vigilância, implicava provar a culpa pelo não emprego das diligências necessárias e destinadas a evitar os danos.

Admitimos com facilidade o primeiro pressuposto, isto é, que impenda sobre o ente público que detém e utiliza o drone um efetivo dever de vigilância, pois não se vislumbram razões para supor um regime diferenciado para este equipamento (admitindo que se trata, com efeito, de um equipamento e já não de um agente, como conjeturámos supra).

Porém, aventar a culpa do ente público pelos danos causados por Alpha 3 exige juízos particularmente difíceis. Talvez por essa razão, outra norma figura no regime da responsabilidade civil extracontratual do Estado (no artigo $11 .^{\circ}$ ) que, excluindo totalmente o pressuposto da culpa da equação da responsabilidade civil, alcança oferecer uma resposta mais clara ao problema.

Ao abrigo desta norma, o Estado e as demais pessoas coletivas de direito público respondem pelos danos decorrentes de atividades, coisas ou serviços administrativos especialmente perigosos, salvo quando, nos termos gerais, se prove que houve força maior ou concorrência de culpa do lesado (...).

Os entraves à aplicação desta norma decorrem sobretudo da caracterização de uma atividade como "especialmente perigosa», pois as fontes do direito não nos oferecem critérios de valorização abstrata da especial perigosidade e, havendo uma clara zona de sobreposição da lei especial face à lei geral, a jurisprudência terá aqui um papel determinante. Acompanhamos, pois, Carla Amado Gomes, quando constata que a perigosidade deveria estar ao menos minimamente caracterizada, e ser aferida em abstrato, e não em concreto, por uma questão de segurança jurídica ${ }^{83}$. Na verdade, não dispomos de critérios precisos para caracterizar a perigosidade da utilização de robôs, atividade que, em si mesma, não parece acarretar num risco anormal de provocar danos, sobretudo quando comparada com a mesma atividade quando executada por seres humanos, onde estes são claramente mais falíveis.

A tendência será, pois, a de qualificar, em concreto, determinadas atividades do Estado como especialmente perigosas, como elemento consubstanciador de uma ilicitude a jusante. Via de refugo, há que dizê-lo, para fazer face a um problema que, de outro modo, corria o risco de ter como resposta a ausência de fundamento indemnizatório no plano extracontratual. O que demonstra, por um lado, a importância major da configuração da responsabilidade sem culpa e, por outro lado, a impreparação natural do direito

83 Carla Amado Gomes, "Nota breve sobre a tendência de objectivação da responsabilidade civil...", cit., p. 98. 
para responder a exigências dos tempos atuais, que obrigam a configurar danos desconhecidos e/ou não imputáveis a sujeitos precisos.

Pela nossa parte, não podemos afirmar que a solução atualnos pareça totalmente satisfatória, essencialmente porque, devido à sua capacidade de tomar decisões com relevância ética, e ao facto de ocuparem funções tipicamente humanas, nos parecer que as «máquinas éticas» deveriam ser, para certos efeitos, consideradas agentes ou usufruir de um estatuto intermédio. A breve trecho, parece-nos, os juristas não poderão furtar-se a refletir, a propósito da interação entre robôs e humanos, sobre aquele que é provavelmente o problema mais preponderante da atualidade jurídica - a relação entre a imputação e a exigibilidade.

O problema da natureza do robô, e da sua possível comparação com um ser humano, assume especial importância no Caso 2. Aqui, o robô Alpha 4 desempenha funções de auxiliar de serviços gerais numa unidade de saúde mental privada, levando a cabo atividades análogas às dos restantes funcionários da referida unidade. Não se trata de ficção científica, mas de algo que se generalizará muito em breve.

Sucedeu que, ao imobilizar uma doente, com o fim de evitar que esta se magoasse e/ou magoasse outros doentes, a doente caiu e, devido à queda, veio a falecer. Deixaremos de lado as hipóteses de concorrência de culpa do lesado, bem como a possibilidade de a morte ter ficado a dever-se a determinadas características da doente, ao seu fluxo sanguíneo ou à medicação que toma. Vamos, portanto, supor que existe causalidade entre a queda de Amélia e a sua morte, provocada por um ato ou omissão de alguém.

Se admitíssemos que Alpha 4 deve equiparar-se, para este efeito, a qualquer outro funcionário, deveríamos começar por avaliar a sua culpa, vale dizer, verificar se o robô atuou com negligência ou se, pelo contrário, cumpriu escrupulosamente as regras de segurança necessárias. Se concluíssemos pela verificação da culpa do robô no caso concreto, poderíamos imediatamente lançar mão do disposto no artigo 500. ${ }^{\circ}$ do Código Civil, situando a questão no âmbito da responsabilidade do comissário pelos atos do comitente. De todo o modo, esta via de responsabilização sempre dependeria, por um lado, de aceitar que Alpha 4 é um comissário da unidade de saúde onde presta a sua atividade e ainda, por outro lado, de convir em que o robô é capaz de culpa, verificando-se a sua negligência, pois só neste caso haverá obrigação de indemnizar. Esta é, portanto, uma solução que só se coloca no domínio do hipotético.

Não obstante, este rumo hipotético parece-nos melhor do que o recurso ao já aludido artigo 493. ${ }^{\circ}$ do Código Civil, e por estas razões: sendo Alpha 
4 uma máquina autónoma, cujo comportamento não é monitorizado ou controlado por seres humanos, a unidade de saúde ilidiria facilmente a presunção de culpa que sobre si impende. Na verdade, não havia nada que se pudesse fazer para evitar a ação de Alpha 4. Aceitando que este robô desempenha funções em tudo idênticas às de um ser humano, esta hipótese parece ficar de fora do âmbito da "culpa in vigilando", que definitivamente não foi pensada para robôs autónomos. Além do mais, não pode afirmar-se que a conduta de Alpha 4 pareça perigosa - a ser-se rigoroso, a ação de qualquer ser humano é, em geral, mais falível que a de um robô. Neste sentido, e como já referimos, seria difícil fundamentar que a atividade deste auxiliar mecânico é, por si só, mais perigosa que a de qualquer auxiliar humano, só por essa razão. De resto, o caso concreto não parece apontar para um caráter especial ou excecional desta atividade; é algo que poderia perfeitamente ocorrer se este auxiliar fosse humano, e não robô.

\section{Notas para o futuro}

O que imediatamente se retira do precedente é que o sistema jurídico atual não está preparado para enfrentar com diligência este tipo de situações, e elas trarão novos modos de pensar a responsabilidade. Desde logo, por acentuarem o problema de discernir os danos «evitáveis» dos danos «inevitáveis»: pelos danos evitáveis poderão eventualmente ser responsabilizados os vigilantes, os proprietários ou, por defeito de fabricação, os produtores dos robôs em causa; mas os danos inevitáveis, em nosso parecer, são hoje irressarcíveis.

Futuramente, nas relações de responsabilidade entre humanos e robôs, determinados institutos jurídicos poderão ser trabalhados no sentido de adequar as soluções, nomeadamente: a) a exigência de consentimento informado para ser tratado por um robô; b) uma redefinição da responsabilidade do produtor relativamente à disponibilização de atualizações e respetivos deveres de informação; c) uma clara obrigação de updating por parte de quem beneficia do trabalho de robôs autónomos; d) a existência de seguros/fundos de garantia concernentes à utilização de robôs. Não cabe na economia do presente artigo tratar cada uma destas questões, mas estamos em crer que estes são vértices fundamentais na construção de um modelo doutrinário suficientemente aturado e abrangente.

«De iure condendo", parece-nos que uma solução razoável seria idêntica àquela que se encontrou para os danos causados por animais, tal qual se acha postulada no artigo 502. ${ }^{\circ}$ do Código Civil, ou seja, uma nova linha de 
autêntica responsabilidade pelo risco. «De iure condendo», pois não nos parece que os danos provocados por robôs se encontrem abrangidos pela relevância problemática da norma dedicada aos animais, o que invalida uma extensão da norma ${ }^{84}$. Em alternativa, ou cumulativamente, poderia ponderar-se a proposta do Draft Report With Recommendations to the Comission on Civil Law Rules on Robotics, do Parlamento Europeu (31/05/2016), no sentido de constituir um Fundo de Garantia para robôs autónomos ${ }^{85}$.

Isto, pelo menos até ao momento em que os robôs estejam de tal modo envolvidos com os humanos, repartindo a sua vivência quotidiana, os seus costumes, e partilhando dos seus valores - o que inevitavelmente acontecerá - que comece a parecer estranho que, sendo já seres autenticamente éticos, não sejam, eles próprios, responsabilizados. Nesse dia, estamos em crer, não perguntaremos se a ação danosa de um robô foi culposa, perguntaremos se lhe era requerido atuar de outra forma, tendo em conta as circunstâncias e o meio em que atuou. Nesse dia, teremos já concluído, provavelmente, que a censura jurídica se esgota nesse juízo, nessa ponderação despida do pecado e do castigo, na qual importa sobretudo que os danos sejam ressarcidos quando tal corresponda a uma expectativa do lesado que a ordem jurídica, de algum modo, legitime.

84 Solução que sempre acarretaria problemas, alguns óbvios, outros nem tanto. Veja-se António Pinto Monteiro, "A Indemnização por Danos não Patrimoniais em Debate: também na responsabilidade contratual? Também a favor das pessoas jurídicas? in Revista Brasileira de Direito Comparado, n. ${ }^{\circ} 46$, 1. ${ }^{\circ}$ semestre 2014, pp. 13 a 33.

85 Cfr. Artigo $47 .^{\circ}$ do Decreto Lei n..$^{\circ}$ 291/2007, de 21 de agosto: Fundo de Garantia Automóvel 1 - A reparação dos danos causados por responsável desconhecido ou isento da obrigação de seguro em razão do veículo em si mesmo, ou por responsável incumpridor da obrigação de seguro de responsabilidade civil automóvel, é garantida pelo Fundo de Garantia Automóvel nos termos da secção seguinte. 2 - 0 Fundo de Garantia Automóvel é dotado de autonomia administrativa e financeira. 3 - Os órgãos do Instituto de Seguros de Portugal asseguram a gestão do Fundo de Garantia Automóvel. 4 - 0 Fundo de Garantia Automóvel, existente nos termos do Decreto-Lei n. ${ }^{\circ} 522 / 85$, de 31 de dezembro, mantém todos os seus direitos e obrigações. 5 - 0 Fundo de Garantia Automóvel pode efetuar o resseguro das suas responsabilidades. 